\title{
Microstrip Antenna Design for Femtocell Coverage Optimization
}

\author{
Afaz Uddin Ahmed, ${ }^{1}$ M. T. Islam, ${ }^{1}$ Rezaul Azim, ${ }^{1}$ \\ Mahamod Ismail, ${ }^{2}$ and Mohd Fais Mansor ${ }^{2}$ \\ ${ }^{1}$ Institute of Space Science (ANGKASA), Universiti Kebangsaan Malaysia, UKM, 43600 Bangi, Selangor, Malaysia \\ ${ }^{2}$ Department of Electrical, Electronic and Systems Engineering, Universiti Kebangsaan Malaysia, UKM, 43600 Bangi, \\ Selangor, Malaysia
}

Correspondence should be addressed to M. T. Islam; titareq@yahoo.com

Received 4 November 2013; Accepted 2 December 2013; Published 3 April 2014

Academic Editor: J.S. Mandeep

Copyright (C) 2014 Afaz Uddin Ahmed et al. This is an open access article distributed under the Creative Commons Attribution License, which permits unrestricted use, distribution, and reproduction in any medium, provided the original work is properly cited.

\begin{abstract}
A mircostrip antenna is designed for multielement antenna coverage optimization in femtocell network. Interference is the foremost concern for the cellular operator in vast commercial deployments of femtocell. Many techniques in physical, data link and networklayer are analysed and developed to settle down the interference issues. A multielement technique with self-configuration features is analyzed here for coverage optimization of femtocell. It also focuses on the execution of microstrip antenna for multielement configuration. The antenna is designed for LTE Band 7 by using standard FR4 dielectric substrate. The performance of the proposed antenna in the femtocell application is discussed along with results.
\end{abstract}

\section{Introduction}

Femtocell, also known as femtocell access point (FAP), is a short-ranged, low-powered, and low-cost base station that has been shrunk down to the size of a paperback book. Femtocell is similar to a wireless internet router and easy to install in offices and residences. It is a mini base station for the indoor coverage purpose and an extension of outdoor network. It provides high quality indoor coverage and increases the capacity of the network by diverting a portion of the traffic through wired-backhaul connection [1]. Cellular operators throughout the world are facing challenges in increasing system capacity, coverage, and residential connectivity in suburban and urban environments due to the huge investment that follows. Femtocell offers an economically appealing way to improve the quality, coverage, and the service of the existing network. However, dense deployment of femtocell induces interference concern, which remains a strong challenge so far $[2,3]$. Moreover, the indoor wireless environment and short distances among the cells have made the situation more complex. Since the cellular operators prefer cochannel deployment for better spectral efficiency, femtocell increases the capacity without considering the fairness of per femtocell user capacity.

Network planner has no control over femtocells deployment. Femtocell has extensive autoconfiguration capability to ensure plug and play deployment [4]. For successful residential deployment, several technical challenges need to be overcome. Large-scale deployment of femtocell in dense area increases the mobility events and overshoots the network subscribers in an unwanted level. Femtocell is usually placed in the corner of any residential places or offices where the wire connection is easier. Therefore, instead of omnidirectional antenna, multielement antenna is better to optimize the coverage area. Such a switched based multielement antenna configuration is proposed in [5]. Switching between the antennas makes it easy to optimize the coverage by controlling a simple circuit. Femtocell switches off the antenna at that direction where there is no user, thus lowering the chances of intercell interferences. Another coverage optimization tactic using multielement antenna with tunable attenuator is shown in [6]. Tunable attenuator is a reliable option for coverage optimization. It tunes up the radiation power to confirm the required radiation pattern. Since a power amplifier for 


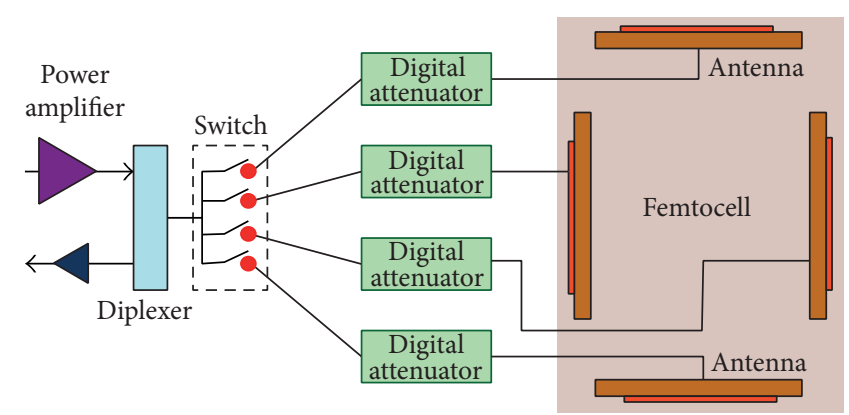

FIGURE 1: Multielement antenna configuration in femtocell (microstrip antenna).

each antenna will be costly for commercial use, a common power amplifier with digital actuator for each branch is conventional.

Multielement antenna in femtocell application divides the coverage area into multisections and each of the antennas occupies same portion of scanning-area. As such, four directional antennas have the angular coverage of $90^{\circ}$ for each of them.

In this paper, a microstrip antenna is designed for multielement antenna configuration for femtocell coverage optimization (Figure 1). The performance of the antenna is simulated in a 4-element femtocell like assembly. The antenna design and substrate choice result in a flexible beam forming in femtocell application. The rest of the paper is arranged as follows: antenna design in Section 2, results in Section 3, array configuration in femtocell in Section 4, discussion in Section 5, and conclusion in Section 6.

\section{Antenna Design}

Inside the femtocell, the available space is limited for antenna patterns. Only few antenna types are possible for femtocell operation, for example, planner inverted $\mathrm{F}$ antenna, microstrip antenna, and wire antenna [7-11]. Microstrip antenna is a smart solution for small, efficient, and economical wireless communication system. Features like small size, light weight, low profile, low assembly cost, ease of mounting on the surface, and integration with printed circuits board (PCB) enable its use in a wide range of wireless appliances $[12,13]$. However, compared with the nonprinted antennas, it has few disadvantages, for example, poor radiation pattern due to the excitation of surface wave, narrow impedance bandwidth, and low gain. Since the femtocell coverage region is small (around $10 \mathrm{~m}$ ), microstrip antenna is a suitable choice for a multielement femtocell configuration. It is capable of miniaturing design and cost effective solution [14-16]. However, to improve the bandwidth, radiation-efficiency, and directivity of the patch antenna, there are methods that use thick substrate, low dielectric substrate, multiresonator, stack configurations, and various impedance matching and feeding techniques. The use of substrates with low thickness and permittivity helps to reduce the dimension of the antennas [17]. One of the methods of widening the bandwidth is using slot on the patch of different shapes such as I, H, M, and $U$ $[18,19]$.

The patch antenna in this paper is designed for LTE Band 7. It is widely used in European, South American, Australian, Asian, and African regions [20, 21]. It has one of the highest bandwidth among the LTE bands and it is suitable for femtocell operation. LTE Band 7 has uplink from $2500 \mathrm{MHz}$ to $2570 \mathrm{MHz}$ and downlink from $2620 \mathrm{MHz}$ to $2690 \mathrm{MHz}$. Therefore, the coverage bandwidth of the antenna is from $2.5 \mathrm{GHz}$ to $2.7 \mathrm{GHz}$. Substrate FR4 is used to design the antenna. FR4 is a low cost and available substrate and popular for commercial microstrip antenna production.

The length and width calculation of the antenna is determined by using the following formulas.

The width of the patch is given by Bhartia et al. [22] as

$$
W=\frac{c}{2 f_{r} \sqrt{\left(\varepsilon_{r}+1\right) / 2}}
$$

where $f_{r}$ and $\varepsilon_{r}$ are resonant frequency and relative dielectric constant of the substrate, respectively.

Now, the effective dielectric constant is expressed by Gilb and Balanis [23] as

$$
\varepsilon_{e}=\frac{\varepsilon_{r}+1}{2}+\frac{\varepsilon_{r}-1}{2}\left[1+12 \frac{h}{W}\right]^{-1 / 2},
$$

where $h$ is the height of dielectric substrate.

The actual length of the patch is given by [9] as

$$
L=\frac{c}{2 f_{r} \sqrt{\varepsilon_{e}}}-2 \Delta L,
$$

where $\Delta L$ is the extension of the patch length on both ends of the patch that is given by Hammerstad [24] as

$$
\Delta L=0.412 h \frac{\left(\varepsilon_{e}+0.3\right)((W / h)+0.264)}{\left(\varepsilon_{e}-0.258\right)((W / h)+0.8)} .
$$
[9]

The ground-plane length and width can be calculated as

$$
\begin{gathered}
L_{g}=6 h+L, \\
W_{g}=6 h+W .
\end{gathered}
$$




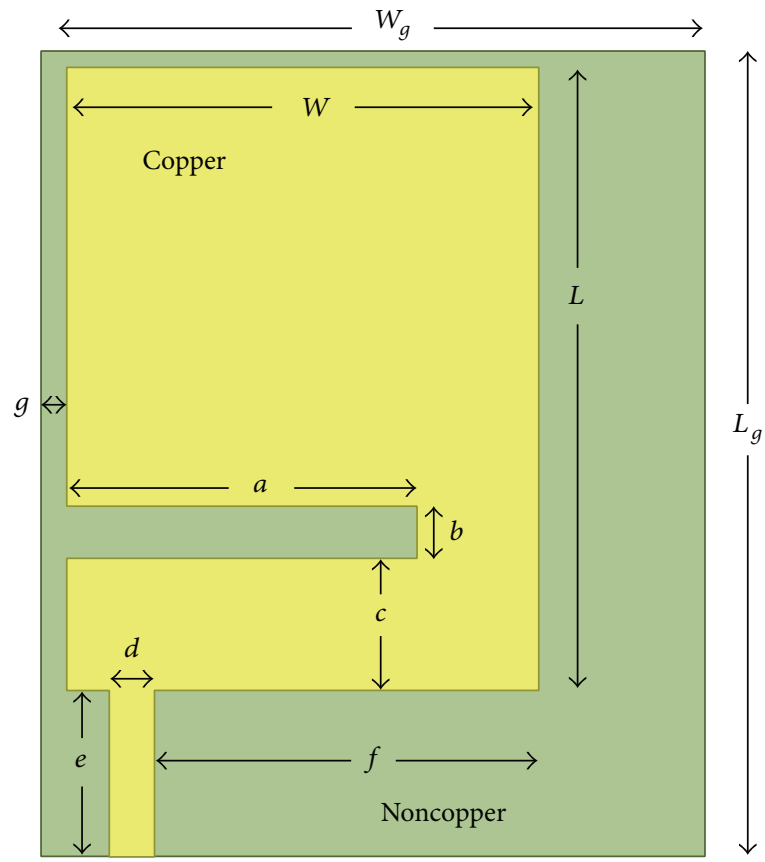

FIGURE 2: Design layout of the proposed antenna.

TABLE 1: Design specification parameters.

\begin{tabular}{lcccccccccc}
\hline Parameters & $a$ & $b$ & $c$ & $d$ & $E$ & $f$ & $g$ & $L$ & $W$ & $L_{g}$ \\
\hline Unit $(\mathrm{mm})$ & 20 & 3 & 7.5 & 2.5 & 9.5 & 21 & 0.5 & 35.5 & 27 & 46 \\
\hline
\end{tabular}

The beamwidth of each microscript antenna and the resultant of any two particular antenna elements is a key fact in antenna designing. For design flexibility, two resonant frequencies were considered to safeguard the whole band coverage. Though the band is not that wide, two resonant points are taken so that it cutbacks the narrow beamwidth characteristics of the patch antenna. The resonant frequencies are about the middle points of the uplink and downlink bands: $2.53 \mathrm{GHz}$ and $2.66 \mathrm{GHz}$. The theoretically calculated patch length and width for the two frequencies are $35.5 \mathrm{~mm}$ and $27.3 \mathrm{~mm}$ and $26 \mathrm{~mm}$ and $34 \mathrm{~mm}$, respectively. The parameter for these two frequencies is then optimized with a rectangular slot in the lower middle portion of the patch. The dimension and position of the slot are also optimized according to the full coverage of the bandwidth [25]. The opposite copper layer of the substrate is considered as the ground plane. The antenna and array structure are modelled through a commercially available finite element package CST Studio Suite. The main patch is set on the top with $1.6 \mathrm{~mm}$ FR4 dielectric substrate with relative permittivity of 4.6 and tangent loss of 0.02 . Figure 2 shows the dimension of the antenna and Table 1 contains the overall design specification parameters.

Rectangular shape microstrip antenna is a basic shape in antenna engineering field. However, the intention of designing is to keep it as simple as possible. The antenna is excited with general microstrip line-feeding technique. The

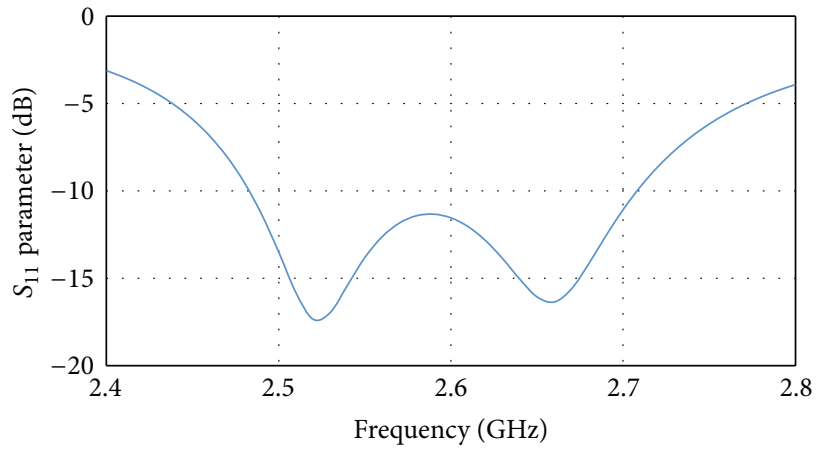

Figure 3: $S_{11}$-parameter of the designed antenna.

advantage of this method is that the connection of the patch and the feed is direct and all on the same substrate to provide planar structure $[26,27]$.

\section{Results Analysis}

The impedance bandwidth of the antenna is given in Figure 3 . The return loss $\left(S_{11}\right)$ of the antenna is $<-10 \mathrm{~dB}$ ranging from 2.48 to $2.71 \mathrm{GHz}$. Two resonant frequencies overlap with each other covering the required uplink and downlink of LTE Band 7. 


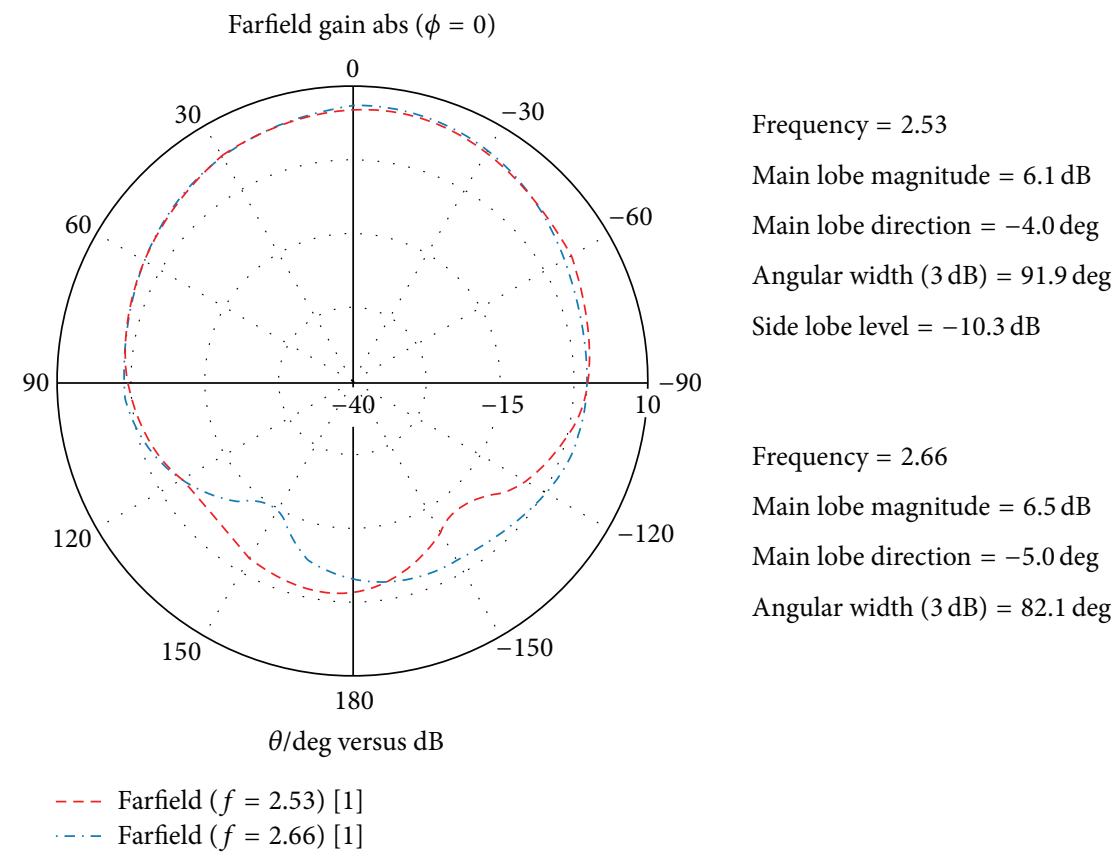

FIgURE 4: Radiation pattern at $2.53 \mathrm{GHz}$ and $2.66 \mathrm{GHz}$.

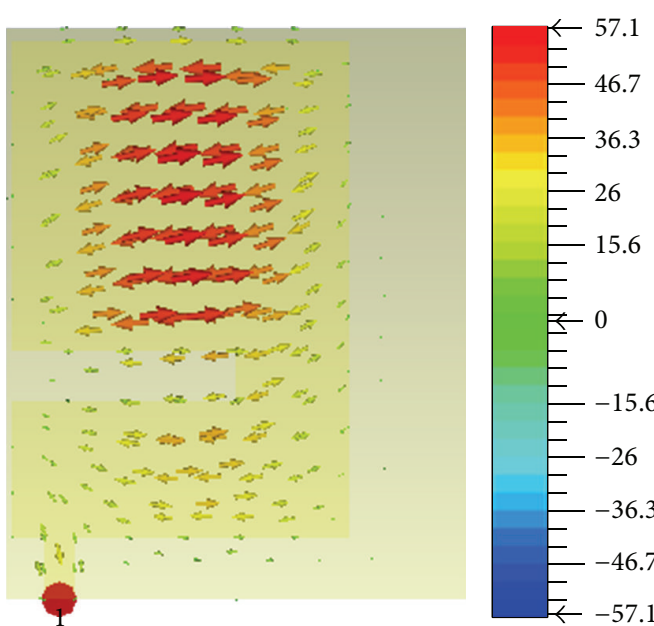

Surface current $(f=2.53)[1]$ (peak)

3D maximum: 56.62

Frequency: 2.53

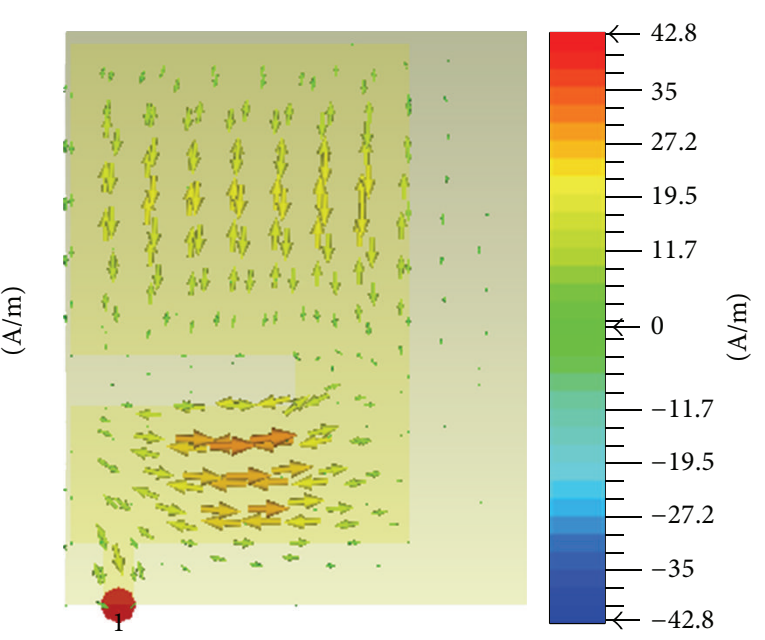

Surface current $(f=2.66)[1]$ (peak)

3D maximum: 42.23

Frequency: 2.66

(a)

(b)

FIgURE 5: Surface current on the patch at (a) $2.53 \mathrm{GHz}$ and (b) $2.66 \mathrm{GHz}$.

Figure 4 illustrates the radiation characteristics of the antenna at $2.53 \mathrm{GHz}$ and $2.66 \mathrm{GHz}$. In both frequencies, it shows broad beam and maximum radiation at the front side. The direction of the main lobes is almost at $0^{\circ}$. Besides, the peak-gains are $6.1 \mathrm{~dB}$ and $6.5 \mathrm{~dB}$ in $2.53 \mathrm{GHz}$ and $2.66 \mathrm{GHz}$, respectively. However, the backward radiation in the measurement cannot be ignored. Since the antennas are placed in the outer surface of the house that contains the circuitry board of the femtocell, a shielding plane or cavity can reduce the backward radiation level. However, a shielded plane can reduce the antenna efficiency, while cavity can narrow down the beamwidth [28-30].

Figure 5 shows the current density on the antenna patch. At $2.53 \mathrm{GHz}$, maximum surface current density occurs on the middle of the patch and above the slot. However, at $2.66 \mathrm{GHz}$, the maximum surface current shifts to lower portion of the slot. For uplink and downlink bands, different side of the slot on the patch gets higher surface current density. 


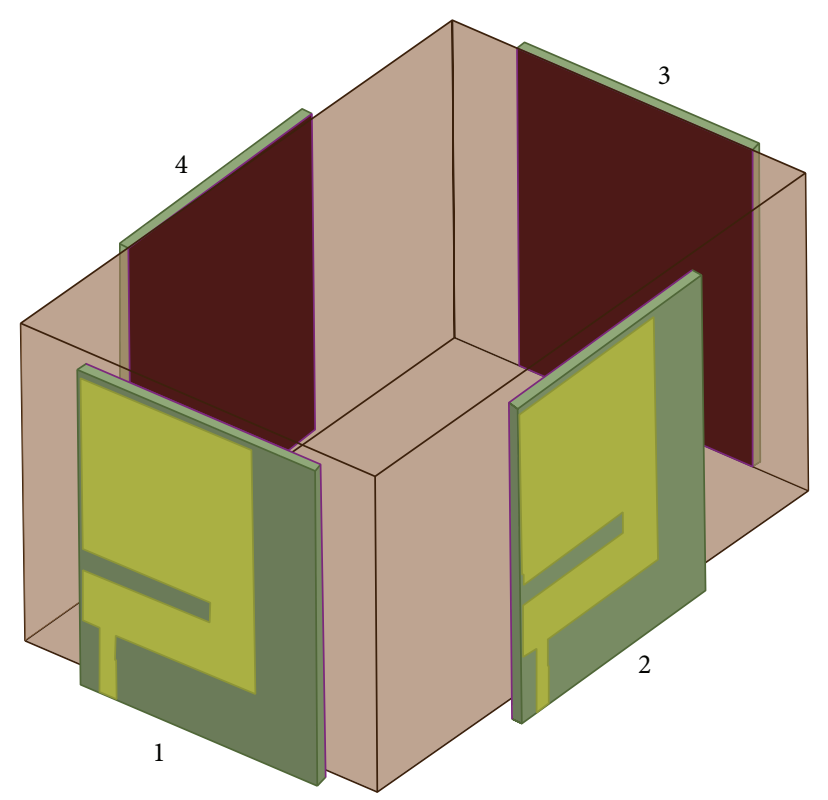

Figure 6: Multielement antenna configuration.

\section{Array Configuration in Femtocell Application}

Single antenna femtocell with coverage optimization feature can help very little in interference reduction. Due to omnidirectional radiation pattern, it cannot optimize its radiation pattern according to the shape of the house and users' position. A switch based multielement antenna coverage with self-optimization technique can select one or a combination of two or three antennas according to the users' position and the shape of the house. Although single antenna femtocell ensures a faster convergence time comparing with the multielement antenna, it also increases the mobility events that result in unnecessary core network signalling. However, multielement antenna decreases the mobility events and increases the indoor coverage more effectively without overshooting the outdoor users.

To analyse the performance of the antenna in femtocell application, four microscript antennas are placed outside of a rectangular box on the same plane. The four antennas are faced in four directions, mounted on each surface of the box, and separated by uniform angle of $90^{\circ}$ as given in Figure 6 .

Figure 7 (a) illustrates the radiation pattern of the two antennas and their resultant beam that is directed almost at $45^{\circ}$ angle with respect to their individual beams. Figure 7(b) shows the resultant beams of antennas 1 and 2 with variable feeding power through the digital attenuator for each antenna. The higher the amplitude of the feed-signal with respect to one another, the more the resultant beam deflects to that direction. Thus, by changing the power level in each port, the direction and coverage of the resultant beam can be changed. This is an advantage that femtocell can exercise to narrow down the beamwidth to serve a particular subscriber without interfering with other subscribers. Figure 7(b) shows the radiation pattern of four antennas and the resultant combinations. One mentionable effect that might have an array coupling is the spacing between the elements. However, in this case, the directions of the antennas are separated by $90^{\circ}$, so it is not a bigger concern. However, the antennas are positioned keeping the same distance among each other alike the commercially available femtocell.

Finally, Figure 8 shows the resultant path-loss of the antenna combinations. As all the antennas are directed $90^{\circ}$ apart from one another, the side lopes do not have any mentionable effect on their radiations.

\section{Discussion}

The Femtocell operates on the same frequency band along with the existing neighbouring femtocell and outdoor macrocell. Therefore, significant impetus towards the deployment of femtocell in the dense coverage area is essential. The userequipment measurement report (UMR), informs the measurement results on the uplink regarding the coexisting FAPs and macrocell service level. An effective interference detection algorithm senses the UMR and femtocell cooperation message (FCM). Using multielement antenna configuration with adjacent power controller (attenuator), femtocell can choose proper radiation pattern to serve particular home users without overshooting the neighbouring femtocell user or outdoor macrocell user. Assigning the required SINR threshold level will make it more convenient to femtocell to adjust the radiation pattern for each user.

\section{Conclusion}

The design of a microstrip antenna for multielement antenna configuration for femtocell device and analyses of its performance for femtocell operation are presented. The proposed 


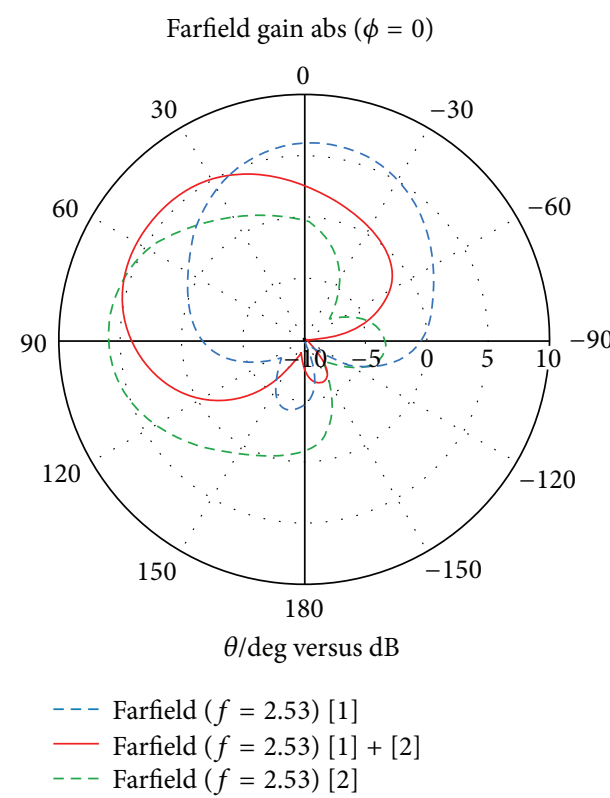

(a)
Farfield gain abs $(\phi=0)$

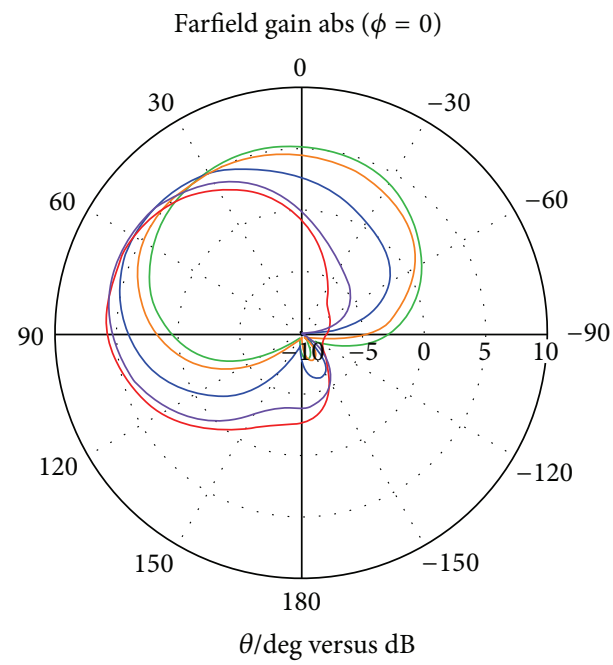

- Farfield $(f=2.53)[1[0.5]+2[1.0]]$
- Farfield $(f=2.53)[1[0.5]+2[1.5]]$
Farfield $(f=2.53)[1[1.0]+2[0.5]]$
Farfield $(f=2.53)[1[1.0]+2[1.0]]$
Farfield $(f=2.53)[1[1.5]+2[0.5]]$

(b)

Farfield gain abs $(\phi=0)$
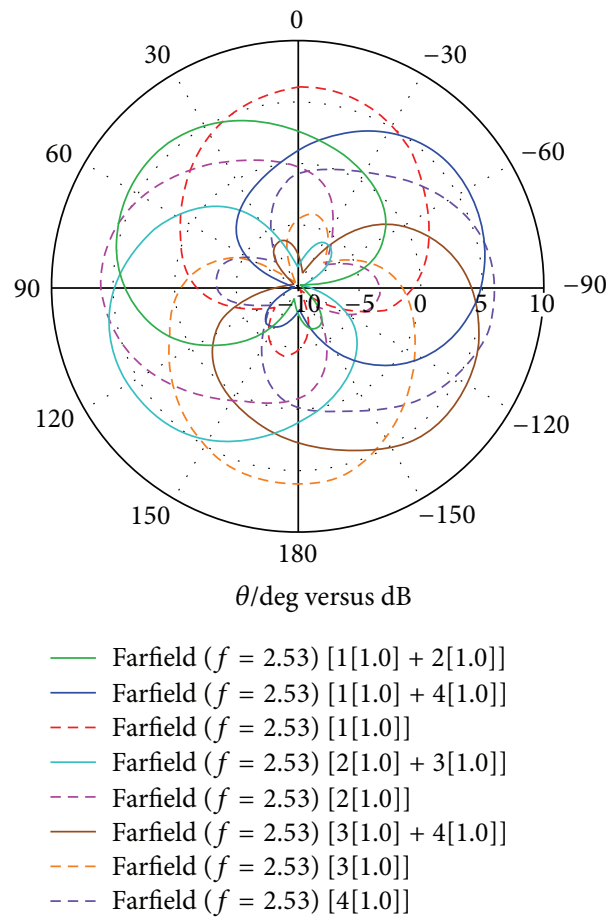

(c)

FIGURE 7: Radiation patters (a) two antennas and their resultant beam, (b) resultant beam of antennas 1 and 2 with different power feeding, and (c) resultant beams of possible combinations. 


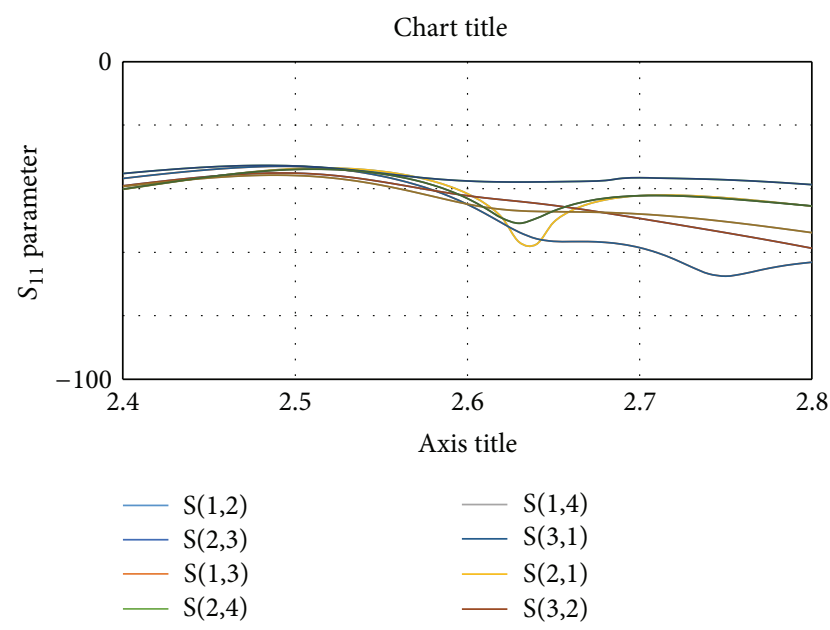

FIGURE 8: $S_{11}$ - parameters for different combination of antennas.

configuration allows each of the four antennas to adjust the pilot power to optimize the antenna coverage. Along with the switching techniques, the microstrip antennas shape up the radiation pattern according to the house model and users' position. The antenna characteristics and the substrate choice indicates that it is suitable for commercial deployment in femtocell devices. It will also reduce the cotier and crosstier interference in dense femtocell network.

\section{Conflict of Interests}

The authors declare that there is no conflict of interests regarding the publication of this paper.

\section{Acknowledgment}

The authors sincerely acknowledge the financial and technical support from Institute of Space Science (ANGKASA), Universiti Kebangsaan Malaysia.

\section{References}

[1] V. Chandrasekhar, J. G. Andrews, and A. Gatherer, "Femtocell networks: a survey," IEEE Communications Magazine, vol. 46, no. 9, pp. 59-67, 2008.

[2] D. López-Pérez, A. Valcarce, G. De La Roche, and J. Zhang, "OFDMA femtocells: a roadmap on interference avoidance," IEEE Communications Magazine, vol. 47, no. 9, pp. 41-48, 2009.

[3] Y.-Y. Li, M. Macuha, E. S. Sousa, T. Sato, and M. Nanri, "Cognitive interference management in 3G femtocells," in Proceedings of the 20th Personal, Indoor and Mobile Radio Communications Symposium (PIMRC '09), pp. 1118-1122, September 2009.

[4] H. Claussen, L. T. W. Ho, and L. G. Samuel, "Self-optimization of coverage for femtocell deployments," in Proceedings of the 7th Annual Wireless Telecommunications Symposium (WTS '08), pp. 278-285, April 2008.

[5] H. Claussen and F. Pivit, "Femtocell coverage optimization using switched multi-element antennas," in Proceedings of the International Conference on Communications (ICC '09), June 2009.
[6] H. Claussen, F. Pivit, and L. T. W. Ho, "Self-optimization of femtocell coverage to minimize the increase in core network mobility signalling," Bell Labs Technical Journal, vol. 14, no. 2, pp. 155-184, 2009.

[7] A. Cabedo, J. Anguera, C. Picher, M. Ribó, and C. Puente, "Multiband handset antenna combining a PIFA, slots, and ground plane modes," IEEE Transactions on Antennas and Propagation, vol. 57, no. 9, pp. 2526-2533, 2009.

[8] Y. Gao, S. Wang, O. Falade, X. Chen, C. Parini, and L. Cuthbert, "Mutual coupling effects on pattern diversity antennas for MIMO femtocells," International Journal of Antennas and Propagation, vol. 2010, Article ID 756848, 8 pages, 2010.

[9] J.-B. Yan and J. T. Bernhard, "Design of a MIMO dielectric resonator antenna for LTE femtocell base stations," IEEE Transactions on Antennas and Propagation, vol. 60, no. 2, pp. 438444, 2012.

[10] A.-H. Tsai, L.-C. Wang, J.-H. Huang, and R.-B. Hwang, "Highcapacity OFDMA femtocells by directional antennas and location awareness," IEEE Systems Journal, vol. 6, pp. 329-340, 2012.

[11] A. T. Mobashsher, M. T. Islam, and N. Misran, "Wideband compact antenna with partially radiating coplanar ground plane," Applied Computational Electromagnetics Society Newsletter, vol. 26, no. 1, pp. 73-81, 2011.

[12] D. M. Pozar, "Microstrip antennas," Proceedings of the IEEE, vol. 80, no. 1, pp. 79-91, 1992.

[13] R. Garg, Microstrip Antennas Design Handbook, Artech House, 2001.

[14] M. T. Islam, M. Moniruzzaman, N. Misran, and M. N. Shakib, "Curve fitting based particle swarm optimization for UWB patch Antenna," Journal of Electromagnetic Waves and Applications, vol. 23, no. 17-18, pp. 2421-2432, 2009.

[15] D. Guha and Y. M. Antar, Microstrips and Printed Antennas: New Trends, Techniques and Applications, John Wiley and Sons, 2011.

[16] N. Nasimuddin, Z. N. Chen, and X. Qing, "Asymmetric-circular shaped slotted microstrip antennas for circular polarization and RFID applications," IEEE Transactions on Antennas and Propagation, vol. 58, no. 12, pp. 3821-3828, 2010.

[17] M. A. Matin, B. S. Sharif, and C. C. Tsimenidis, "Probe fed stacked patch antenna for wideband applications," IEEE Transactions on Antennas and Propagation, vol. 55, no. 8, pp. 2385-2388, 2007.

[18] J. J. Tiang, M. T. Islam, N. Misran, and J. S. Mandeep, "Slot loaded circular microstrip antenna with meandered slits," Journal of Electromagnetic Waves and Applications, vol. 25, no. 13, pp. 1851-1862, 2011.

[19] L. Liu, S. W. Cheung, R. Azim, and M. T. Islam, "A compact circular-ring antenna for ultra-wideband applications," Microwave and Optical Technology Letters, vol. 53, no. 10, pp. 2283-2288, 2011.

[20] W. S. Pan, C. H. Ma, S. H. Shao, and Y. X. Tang, "A 2. 5 GHZ-2. $7 \mathrm{GHz}$ unsymmetrical doherty power amplifier with digital predistortion for LTE-advanced applications," Advanced Materials Research, vol. 760, pp. 546-550, 2013.

[21] E. Dahlman, S. Parkvall, J. Skold, and P. Beming, 3G Evolution: HSPA and LTE For Mobile Broadband, Academic Press, 2010.

[22] P. Bhartia, I. Bahl, R. Garg, and A. Ittipiboon, Microstrip Antenna Design Handbook, Artech House, Norwood, Mass, USA, 2000.

[23] J. P. Gilb and C. A. Balanis, "Pulse distortion on multilayer coupled microstrip lines," IEEE Transactions on Microwave Theory and Techniques, vol. 37, no. 10, pp. 1620-1628, 1989. 
[24] E. Chang, S. A. Long, and W. F. Richards, "An experimental investigation of electrically thick rectangular microstrip antennas," IEEE Transactions on Antennas and Propagation, vol. 34, no. 6, pp. 767-772, 1986.

[25] S. Kibria, M. Islam, and B. Yatim, "Compact dual band RFID reader antenna designed using ramped convergence particle swarm optimization," Przeglad Elektrotechniczny, vol. 89, no. 4, pp. 199-201, 2013.

[26] M. N. Shakib, M. T. Islam, and N. Misran, "Stacked patch antenna with folded patch feed for ultra-wideband application," IET Microwaves, Antennas and Propagation, vol. 4, no. 10, pp. 1456-1461, 2010.

[27] M. T. Islam, A. T. Mobashsher, and N. Misran, "A novel feeding technique for a dual band microstrip patch antenna," IEICE Transactions on Communications, vol. 93, no. 9, pp. 2455-2457, 2010.

[28] M. T. Islam, M. R. I. Faruque, and N. Misran, "Specific absorption rate analysis using metal attachment," Informacije MIDEM, vol. 40, no. 3, pp. 238-240, 2010.

[29] F. Zavosh and J. T. Aberle, "Single and stacked circular microstrip patch antennas backed by a circular cavity," IEEE Transactions on Antennas and Propagation, vol. 43, no. 7, pp. 746-750, 1995.

[30] K.-L. Wong, S.-W. Su, C.-L. Tang, and S.-H. Yeh, "Internal shorted patch antenna for a UMTS folder-type mobile phone," IEEE Transactions on Antennas and Propagation, vol. 53, no. 10, pp. 3391-3394, 2005. 

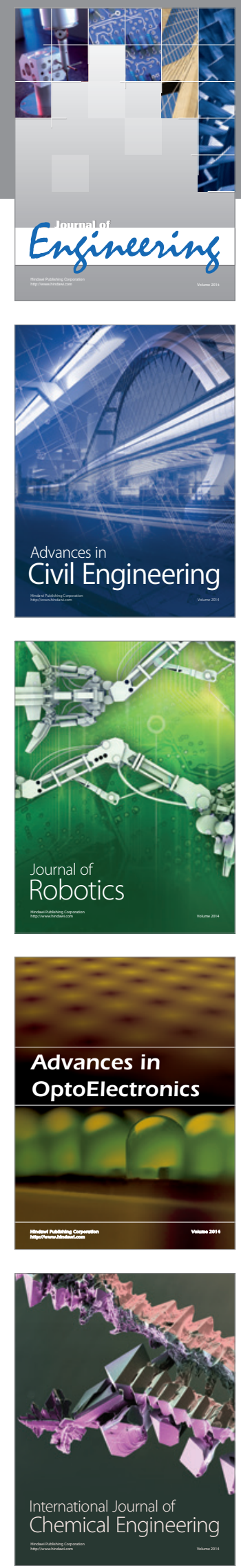

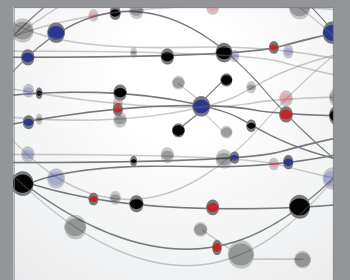

The Scientific World Journal
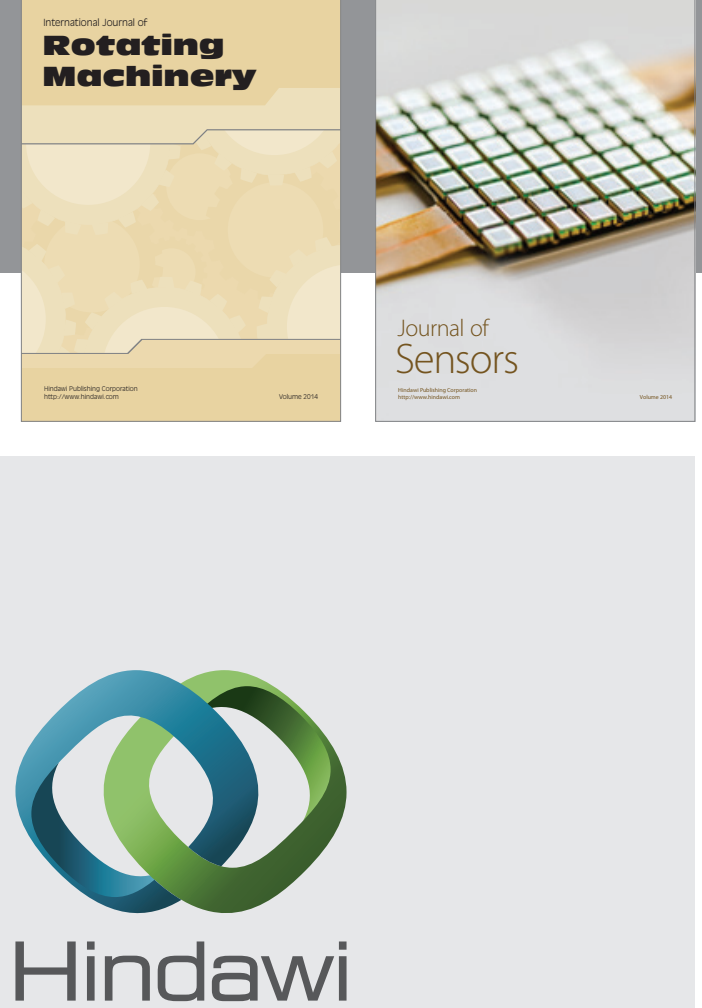

Submit your manuscripts at http://www.hindawi.com
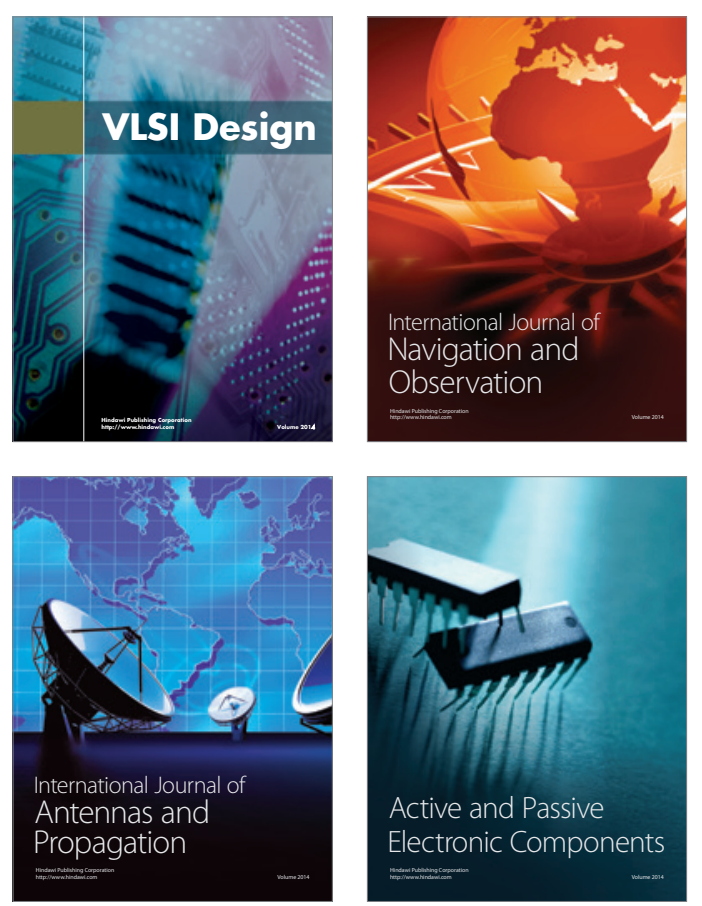
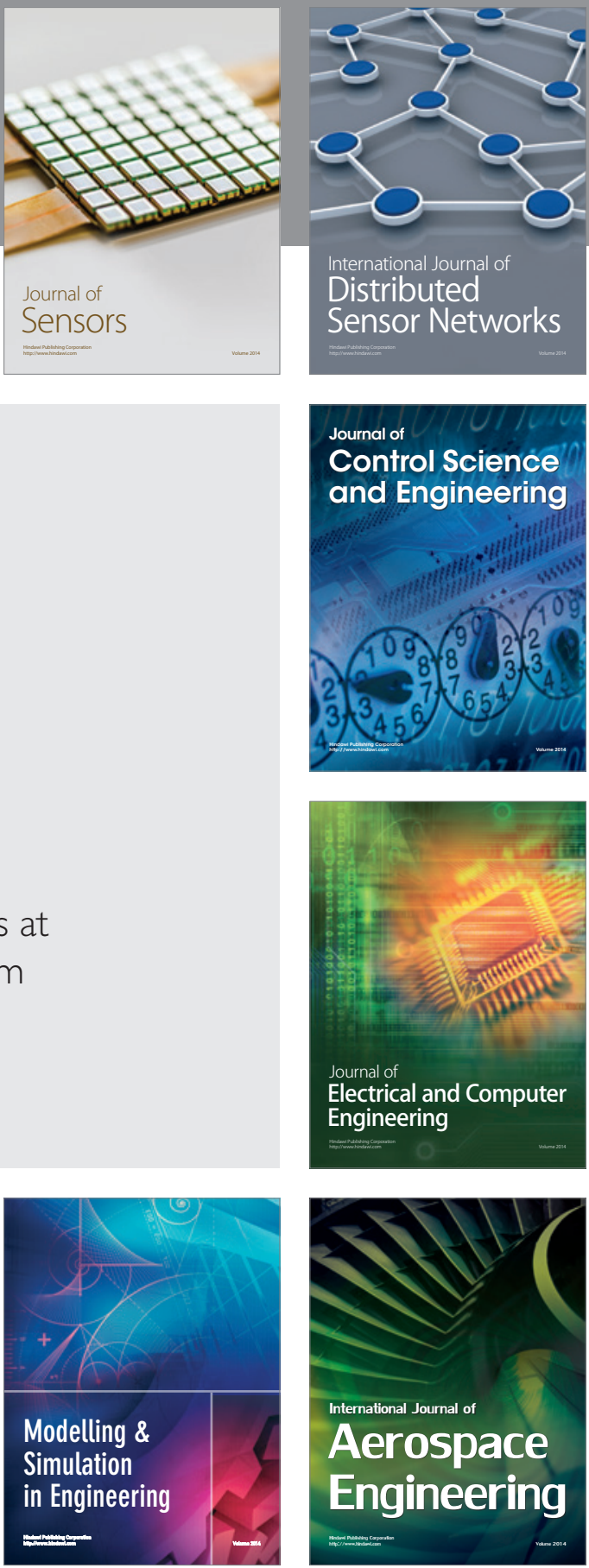

Journal of

Control Science

and Engineering
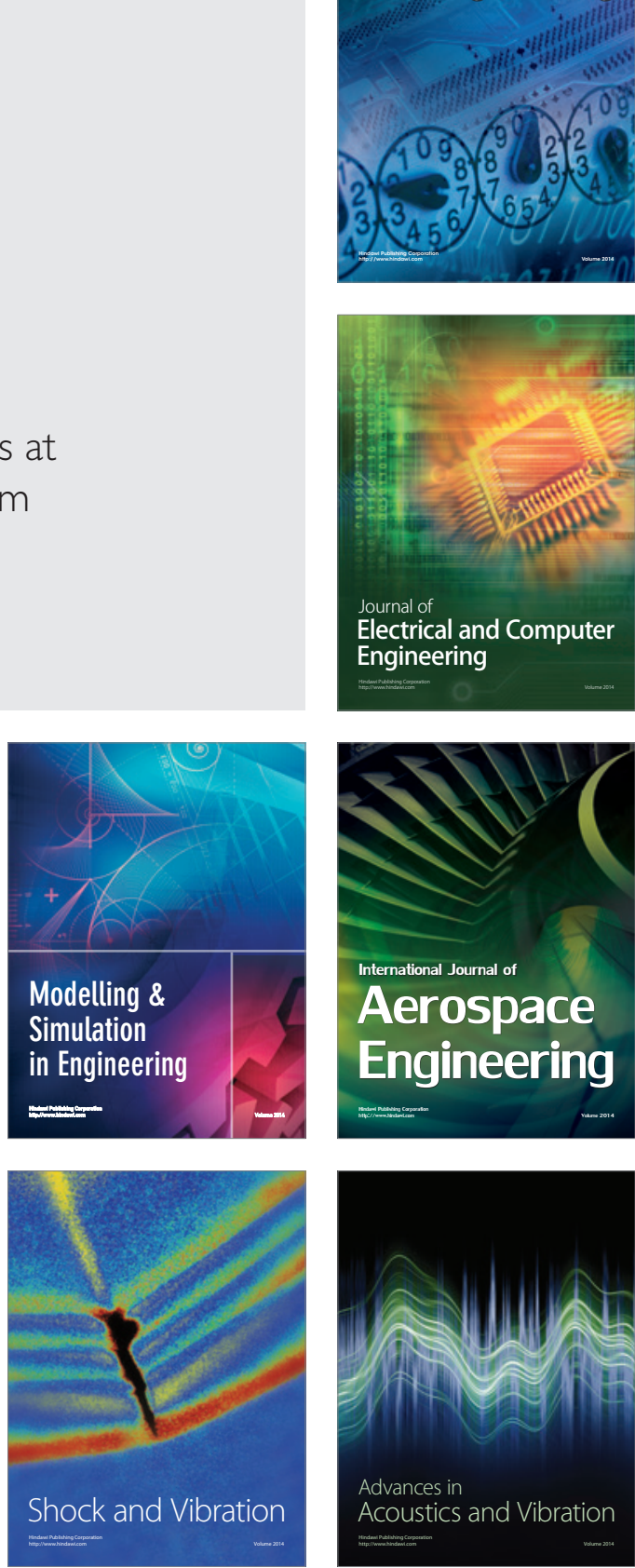